Received: 11 March 2019

Accepted: 15 August 2019

Published online: 27 August 2019

\section{The clinical value and safety of ECG- gated dipyridamole myocardial perfusion imaging in patients with aortic stenosis}

\author{
Fang-Shin Liu ${ }^{1}$, Shan-Ying Wang ${ }^{1,4}$, Yu-Chien Shiau ${ }^{1}$ \& Yen-Wen Wu $\mathbf{u}^{1,2,3,4}$
}

The role of vasodilator myocardial perfusion imaging (MPI) for aortic stenosis (AS) is controversial due to safety and accuracy concerns. In addition, its utility after aortic valve (AV) interventions remains unclear. Patients with AS who underwent thallium-201-gated dipyridamole MPI using a cadmium-zinctelluride camera were retrospectively reviewed and divided into three groups: mild AS, moderate-tosevere AS, and prior AV interventions. Patients with coronary artery disease with $\geq 50 \%$ stenosis, severe

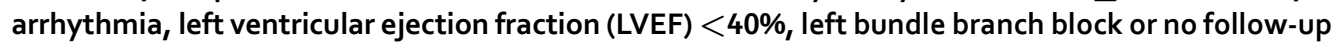
were excluded. Relationships between the severity of AS, clinical characteristics, hemodynamic response, serious adverse events (SAE) and MPI parameters were analyzed. None of the 47 patients had $S A E$, including significant hypotension or LVEF reduction. The moderate-to-severe AS group had higher summed stress scores (SSSs) and depressed LVEF than the mild AS group, however there were no differences after AV interventions. SSS was positively correlated with AV mean pressure gradient, poststress lung-heart ratio (LHRs), and post-stress end-diastolic volume (EDVs) $(P<0.05)$. In multivariate analysis, LHRs and EDVs were independent contributors to SSS. Dipyridamole-induced ischemia and LV dysfunction is common, and dipyridamole stress could be a safe diagnostic tool in evaluation and follow-up in patients with AS.

Aortic valve stenosis (AS) is the most common valvular disorder. Clinical factors such as older age, male sex, smoking, hypertension, diabetes and hypercholesterolemia are important in the progression of $\mathrm{AS}^{1,2}$.

AS can result in microcirculatory dysfunction, defined as abnormalities in myocardial blood flow (MBF) despite the presence of normal left ventricular ( LV) function and normal coronary arteries ${ }^{3,4}$. LV remodeling is attributed to several sequelae: (a) hemodynamic factors including increased LV pressure, reduced coronary perfusion pressure and extravascular compressive forces ${ }^{4,5}$; and (b) pathological changes including myocardial fibrosis and decreased density of vessels in myocardial tissue ${ }^{6}$.

The natural history of AS begins with a prolonged asymptomatic period. In general, mortality is not significantly increased in patients with asymptomatic AS or in those who receive aortic valve (AV) interventions, whereas the mortality is high after the development of symptoms. The management guidelines for patients with severe AS from the American College of Cardiology/American Heart Association Guidelines recommend that patients with equivocal symptoms should receive modified exercise tests ${ }^{5}$. Unfortunately, because of similar risk factors, concomitant coronary artery disease (CAD) in patients with AS is common, and similar symptoms may impede the proper management in this population ${ }^{2,7}$.

There is increasing consensus on the management strategy for patients with coexisting transcatheter aortic valve implantation (TAVI) and percutaneous coronary intervention (PCI $)^{8}$, and single-photon emission computed tomography (SPECT) myocardial perfusion imaging (MPI), a non-invasive examination of last resort, may play an important role in this strategy, especially for those with high operative risk $^{9}$. Nevertheless, the role of vasodilator MPI in patients with significant AS is still controversial due to safety concerns and uncertainty

${ }^{1}$ Department of Nuclear Medicine, Far Eastern Memorial Hospital, New Taipei City, Taiwan. ${ }^{2}$ Division of Cardiology, Cardiovascular Medical Center, Far Eastern Memorial Hospital, New Taipei City, Taiwan. ${ }^{3}$ National Yang-Ming University School of Medicine, Taipei, Taiwan. ${ }^{4}$ Department of Nuclear Medicine, National Taiwan University Hospital and National Taiwan University College of Medicine, Taipei City, Taiwan. Correspondence and requests for materials should be addressed toY.-W.W. (email: wuyw0502@gmail.com) 
over the clinical accuracy. Vasodilator stress decreases systemic blood pressure, which may be unsafe in patients with AS. Given the potential risks, previous guidelines have discouraged stress testing in patients with severe and symptomatic AS, and few studies have investigated the safety of vasodilators stress in these patients ${ }^{10-14}$. Several studies on the presentation of AS with regards to MBF and subsequent myocardial flow reserve (MFR) derived from dynamic MPI have been published in recent years, however no definite characteristics have been found on conventional MPI imaging ${ }^{4,6,15-18}$. In addition, its utility in detecting myocardial ischemia in patients after aortic valve (AV) interventions has not been established ${ }^{15}$. The purpose of this study was to evaluate the efficacy and safety of dipyridamole stress SPECT MPI in patients with AS and after AV interventions.

\section{Results}

Patients characteristics. Forty-seven patients with AS were included in this study (Table 1). The mean age of the patients was $75.3 \pm 10.2$ years, and $34 \%(n=16)$ were male. Twenty-seven patients had mild AS, 15 had moderate-to-severe AS, and five had previously received aortic valve replacement (AVR) or TAVI. All patients received clinical follow-up at least 6 months after SPECT MPI, and none had major cardiovascular events.

Most of the post-AVR/TAVI group had normal or slightly dilated LV, fair left ventricular ejection fraction (LVEF) (i.e. $\mathrm{LVEF} \geq 50 \%$ ) and a trans-valvular pressure gradient $>20 \mathrm{mmHg}$ before the AV intervention. The severity of AS greatly improved after the intervention [AV mean pressure gradient $(P G)=7.09 \pm 4.62$ ]. The time interval between the index MPI and AV intervention ranged from 350 days to more than 30 years.

Comparing groups, the patients in the prior AVR/TAVI group were relatively younger. Except for the higher proportion of patients receiving pacemaker implantation in the prior AVR/TAVI group $(P=0.009)$, there was no significant differences in sex, body mass index (BMI), cardiac risk factors, and other comorbidities including end-stage renal disease, chronic obstructive pulmonary disease/asthma, and right bundle branch block.

Resting doppler echocardiography (UCG). The echocardiographic variables are summarized in Table 2. The patients with moderate-to-severe AS had a significantly higher grade of AS than not only those with mild AS but prior AVR/TAVI group $(P<0.001)$. The mean LVEF measured in the patients with mild AS showed marginal statistical significance compared with the moderate-to-severe AS and prior AVR/TAVI groups $(P=0.058$ and 0.054 , respectively). The AVR/TAVI group had a significantly lower atrial filling (A) velocity than the mild AS group $(P=0.023)$. However, there were no significant differences in left atrial $(\mathrm{LA})$ and LV dimensions and other diastolic parameters between groups $(P>0.05)$.

MPI parameters. The MPI parameters are summarized in Table 3 and Fig. 1. The patients with moderate-to-severe AS had a larger LV size than the other groups, and the patients with moderate-to-severe AS and prior AVR/TAVI had a lower LVEF. Two patients (13.3\%) in the moderate-to-severe AS group had marked RV uptake after stress. Summed stress score (SSS) was significantly higher in the moderate-to-severe AS group compared to the mild AS group $(P=0.007)$, but similar result between the moderate-to-severe AS and prior AVR/ TAVI groups. There were no significant differences in summed rest score (SRS), summed difference score (SDS), post-stress or resting lung-heart ratio (LHRs or LHRr) or stress-induced increased LVEF ( $\triangle \mathrm{LVEF}=$ post-stress LVEF- resting LVEF) among the groups.

Analysis of the contribution of SSS, SRS and SDS. Overall and subgroup analysis were performed to evaluate the contributors to SSS (Table 4, Supplementary Table S1). Increased AV PG, LHRs and LV volumetric data [including post-stress end-diastolic volume (EDVs) and end-systolic volume (ESVs), resting end-diastolic volume (EDVr) and end-systolic volume (ESVr)] were associated with a higher SSS. Due to obvious collinearity, EDVs was chosen as the representative of the LV volume parameters in the multivariate regression analysis. After the multivariate analysis, only increased LHRs and EDVs were independent contributors of SSS.

On the other hand, increased LHRs was the only predictor to SRS $(P=0.014)$, and marginal significance of higher AV PG in multivariate analysis $(P=0.052)$ (see Supplementary Table S2). Larger LV volume were highly correlated with greater SDS $(P=0.022)$ (see Supplementary Table S3). There were no significantly different in patients with native or after AV interventions (see Supplementary Table S4).

In summary, AS severity and LHRs were correlated with higher SSS and SRS, but not SDS. LV volume parameters were independent predictors of SSS and SDS.

There was some difference in LVEF as measured by UCG and SPECT (Table 2 and Fig. 1c) (LVEF UCG $_{\text {vs. }}$ LVEFr between each group, $P=0.055$ vs. $\mathrm{P}<0.001$ ). Bland-Altman plot showed fair agreement but a regression line with a positive slope, indicating systemic bias existed (see Supplementary Fig. S1). Patients with small LV cavity (ESVs $<20 \mathrm{ml}$ ) on gated SPECT had more discrepancy of LVEF between UCG and SPECT (LVEFr-LVEF UCG $^{-}$ of ESVs $<20 \mathrm{ml}$ vs. ESVs $\geq 20 \mathrm{ml}, 6.1 \pm 9.8$ vs. $-10.5 \pm 7.4, P<0.001)$, and higher prevalence of small hearts (ESVs $<20 \mathrm{ml}$ ) in mild AS group.

Safety concerns of dipyridamole stress. Regarding the safety, dipyridamole induced adverse effects in the medical records from the initial study cohort $(n=102)$ were recorded (see Supplementary Table S5), and no severe adverse effects or emergent events were noted, even in patients with documented obstructive CAD $(n=36)$ and significant arrhythmia $(\mathrm{n}=9)$. 


\begin{tabular}{|l|l|l|l|l|}
\hline & $\begin{array}{l}\text { Mild AS } \\
(\mathbf{n}=\mathbf{2 7})\end{array}$ & $\begin{array}{l}\text { Moderate-to-severe AS } \\
(\mathbf{n}=\mathbf{1 5})\end{array}$ & $\begin{array}{l}\text { Post-AVR/TAVI } \\
(\mathbf{n = 5})\end{array}$ & P value \\
\hline Post-AVR/TAVI time (day) & - & - & $\begin{array}{l}2897(350,>30 \\
\text { years) }\end{array}$ & \\
\hline Age (years) & $\begin{array}{l}78.0 \pm 10.0 \\
(61-95)\end{array}$ & $\begin{array}{l}72.8 \pm 8.3 \\
(61-88)\end{array}$ & $\begin{array}{l}68.0 \pm 12.5 \\
(54-82)\end{array}$ & 0.07 \\
\hline Male & $7(25.9 \%)$ & $6(40 \%)$ & $3(60 \%)$ & 0.32 \\
\hline BMI (kg/m $\left.{ }^{2}\right)$ & $\begin{array}{l}25.7 \pm 3.47 \\
(17.7-32.4)\end{array}$ & $\begin{array}{l}25.6 \pm 3.69 \\
(18.8-32.9)\end{array}$ & $\begin{array}{l}24.4 \pm 3.29 \\
(20.5-29)\end{array}$ & 0.768 \\
\hline Cardiac risk factors & $21(77.8 \%)$ & $12(80 \%)$ & $2(40 \%)$ & 0.22 \\
\hline Hypertension & $14(51.9 \%)$ & $4(26.7 \%)$ & $2(40 \%)$ & 0.35 \\
\hline Diabetes mellitus & $15(55.6 \%)$ & $9(60 \%)$ & $1(20 \%)$ & 0.34 \\
\hline Hyperlipidemia & $6(22.2 \%)$ & $55(33.3 \%)$ & $0(0 \%)$ & 0.31 \\
\hline Smoking & \multicolumn{5}{|l}{} \\
\hline Other comorbidities & $3(11.1 \%)$ & $2(13.3 \%)$ & $0(0 \%)$ & $>0.99$ \\
\hline ESRD & $0(0 \%)$ & $1(6.7 \%)$ & $1(20 \%)$ & 0.18 \\
\hline COPD/asthma & $0(0 \%)$ & $0(0 \%)$ & $2(40 \%)$ & $0.009 *$ \\
\hline Post pacemaker implantation & $2(7.4 \%)$ & $0(0 \%)$ & $1(20 \%)$ & 0.2 \\
\hline RBBB & & & \\
\hline
\end{tabular}

Table 1. Clinical characteristics of enrolled patients in three groups. Values are presented as Mean \pm SD (range) or $\mathrm{N}$ (\%) as appropriate [exc. post-AVR/TAVI time is presented as median (range)]. AVR, aortic valve replacement; TAVI, transcatheter aortic valve implantation; $B M I$, body mass index; $E S R D$, end-stage renal disease, estimated glomerular filtration rate $(\mathrm{eGFR})<15 \mathrm{ml} / \mathrm{min} / 1.73 \mathrm{~m}^{2} ; C O P D$, chronic obstructive pulmonary disease; $R B B B$, right bundle branch block. $* P$ value $<0.05$.

\begin{tabular}{|c|c|c|c|c|}
\hline & Mild AS $(n=27)$ & $\begin{array}{l}\text { Moderate-to-severe } \\
\text { AS }(\mathrm{n}=15)\end{array}$ & $\begin{array}{l}\text { Prior AVR/TAVI } \\
(\mathrm{n}=5)\end{array}$ & $P$ value \\
\hline $\mathrm{LA}(\mathrm{mm})$ & $38.1 \pm 4.45$ & $39.9 \pm 4.89(\mathrm{n}=14)$ & $42 \pm 6.16$ & 0.18 \\
\hline IVS (mm) & $11.9 \pm 1.97$ & $12.5 \pm 1.64$ & $11.4 \pm 2.3$ & 0.43 \\
\hline $\mathrm{PW}(\mathrm{mm})$ & $11.5 \pm 1.95$ & $12.3 \pm 1.5$ & $11.8 \pm 2.39$ & 0.41 \\
\hline $\operatorname{LVEDD~}(\mathrm{mm})$ & $45.2 \pm 6.68$ & $47.5 \pm 7.54$ & $44.6 \pm 4.51$ & 0.45 \\
\hline $\operatorname{LVESD}(\mathrm{mm})$ & $27 \pm 4.75$ & $30.3 \pm 6.23$ & $29.4 \pm 4.78$ & 0.18 \\
\hline $\operatorname{LVEF}_{\mathrm{UCG}}(\%)$ & $70.2 \pm 7.46$ & $65 \pm 9.3$ & $62.2 \pm 9.55$ & $0.055^{\S}$ \\
\hline $\mathrm{AV}$ peak flow $(\mathrm{cm} / \mathrm{s})$ & $240 \pm 42.3$ & $324 \pm 63.1$ & $181 \pm 61.9$ & $0.001^{\#}$ \\
\hline AV mean PG (mmHg) & $11.6 \pm 3.67$ & $22.5 \pm 8.62$ & $7.09 \pm 4.62$ & $0.001^{\#}$ \\
\hline TRPG (mmHg) & $25.6 \pm 13(\mathrm{n}=14)$ & $31.2 \pm 15.1(\mathrm{n}=9)$ & $17.3 \pm 1.89(\mathrm{n}=4)$ & 0.21 \\
\hline $\mathrm{E}(\mathrm{cm} / \mathrm{s})$ & $\begin{array}{l}88.5 \pm 27.7 \\
(\mathrm{n}=24)\end{array}$ & $89.1 \pm 37.6(\mathrm{n}=14)$ & $99.4 \pm 52.9$ & 0.99 \\
\hline $\mathrm{A}(\mathrm{cm} / \mathrm{s})$ & $120 \pm 19.2(\mathrm{n}=26)$ & $111 \pm 19.9(\mathrm{n}=13)$ & $89.8 \pm 26.8(\mathrm{n}=4)$ & $0.03^{*}$ \\
\hline E/A ratio & $\begin{array}{l}0.73 \pm 0.19 \\
(\mathrm{n}=26)\end{array}$ & $0.73 \pm 0.18(\mathrm{n}=13)$ & $1.02 \pm 0.7(\mathrm{n}=4)$ & 0.14 \\
\hline DT (ms) & $241 \pm 96.2(\mathrm{n}=25)$ & $241 \pm 153(\mathrm{n}=14)$ & $287 \pm 150(\mathrm{n}=4)$ & 0.29 \\
\hline
\end{tabular}

Table 2. Comparisons of resting Doppler echocardiography in the three groups. Values are presented as mean $\pm \mathrm{SD}$ as appropriate. IVS, interventricular septum; $P W$, posterior wall; $E D D$, end-diastolic dimension; $E S D$, end-systolic dimension; $P G$, pressure gradient; $T R$, tricuspid regurgitation; $E$, the peak early filling velocity of transmitral inflow; $A$, the late diastolic filling velocity of transmitral inflow; $D T$, deceleration time. ${ }^{\$} \mathrm{LVEF}_{\mathrm{UCG}}$ : $P=0.058$ for mild AS vs. moderate-to-severe AS, $P=0.054$ for mild AS vs. prior AVR/TAVI. *AV peak flow and AV mean PG: $P<0.001$ for mild AS vs moderate-to-severe AS, $P<0.001$ for moderate-to-severe AS vs. prior AVR/TAVI. *A: $P=0.023$ for mild AS vs. prior AVR/TAVI.

\begin{tabular}{|l|l|l|l|l|}
\hline & $\begin{array}{l}\text { Mild AS } \\
(\mathbf{n}=\mathbf{2 7})\end{array}$ & $\begin{array}{l}\text { Moderate-to-severe AS } \\
(\mathbf{n = 1 5})\end{array}$ & $\begin{array}{l}\text { Prior AVR/TAVI } \\
(\mathbf{n = 5})\end{array}$ & $\boldsymbol{P}$ value \\
\hline SSS $\geq 4$ & $4(14.8 \%)$ & $7(46.7 \%)$ & $2(40 \%)$ & 0.07 \\
\hline LHRs & $0.35 \pm 0.05$ & $0.37 \pm 0.07$ & $0.39 \pm 0.06$ & 0.2 \\
\hline LHRr & $0.37 \pm 0.05$ & $0.38 \pm 0.07$ & $0.36 \pm 0.08$ & 0.74 \\
\hline Marked RV uptake after stress & $0(0 \%)$ & $2(13.3 \%)$ & $0(0 \%)$ & 0.18 \\
\hline
\end{tabular}

Table 3. Comparison of MPI results in the three groups. Values are presented as mean \pm SD or N (\%) as appropriate. SSS, summed stress score; $L H R s$ or $r$, lung/heart ratio after stress or at rest; $R V$, right ventricular. 

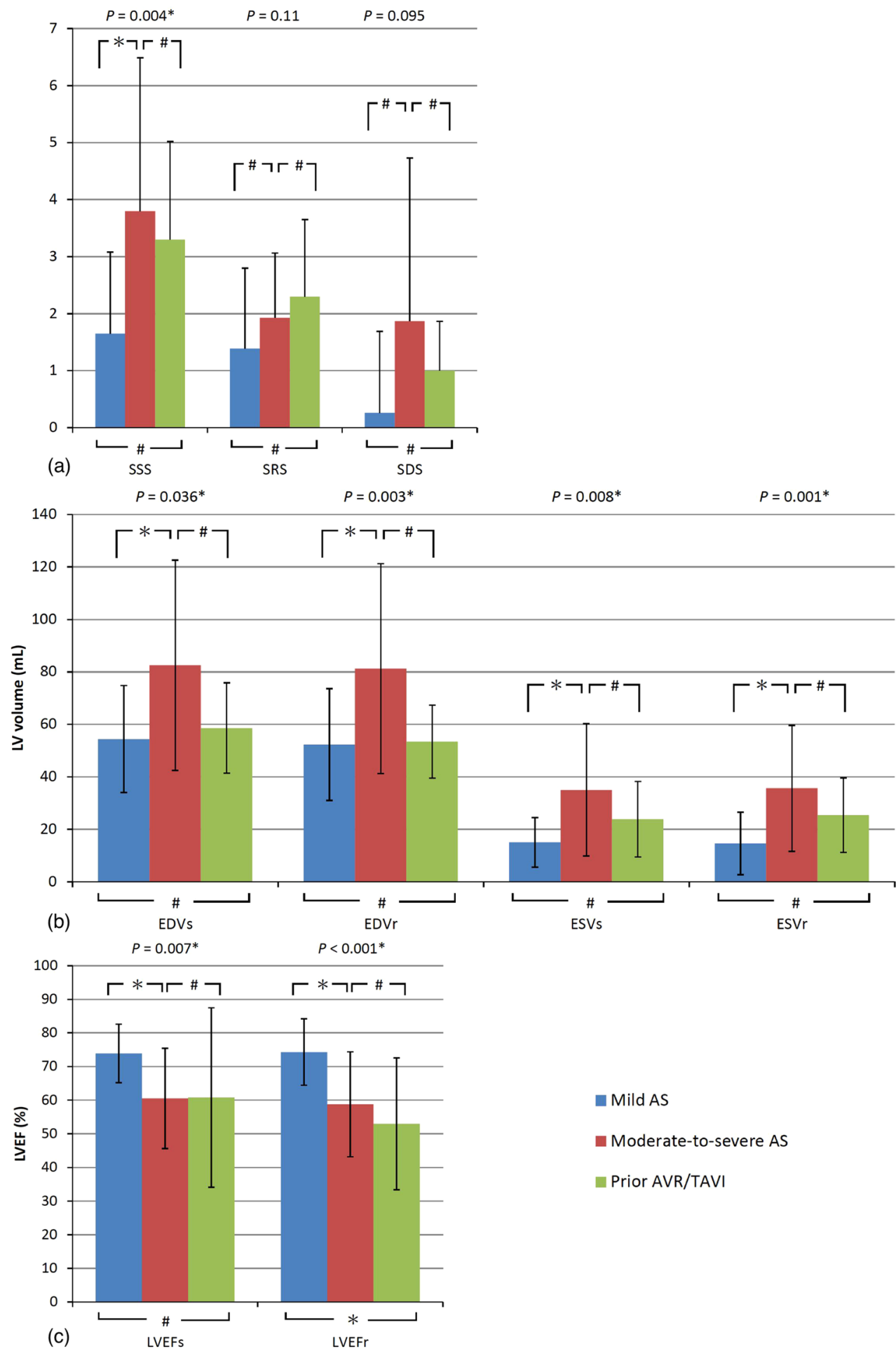

Mild AS

Moderate-to-severe AS

Prior AVR/TAVI

Figure 1. Comparison of the perfusion defects (a), LV volume (b) and LVEF (c) in three groups measured by SPECT MPI. Values are presented as mean \pm SD or $\mathrm{N}(\%)$ as appropriate. SSS, summed stress score; SRS, summed rest score; $S D S$, summed difference score; LHRs or $r$, lung/heart ratio after stress or at rest; EDV, end-diastolic volume; $E S V$, end-systolic volume; $L V E F$, left ventricular ejection fraction. ${ }^{*} P$ value $<0.05 ;{ }^{*} P$ value $\geq 0.05$.

\section{Discussion}

MPI presentation in patients with AS. Few studies have focused on the presentation of perfusion defects on MPI in patients with AS. Pfisterer et al. described reversible apical perfusion defects in patients with AS without $\mathrm{CAD}$, and concluded that they were therefore not specific ${ }^{16}$. Rask et al. demonstrated normal thallium 


\begin{tabular}{|c|c|c|c|c|c|c|c|c|}
\hline \multirow[b]{3}{*}{ Characteristic } & \multicolumn{4}{|c|}{ Univariate analysis } & \multicolumn{4}{|c|}{ Multivariate analysis } \\
\hline & \multirow[b]{2}{*}{ OR } & \multicolumn{2}{|c|}{$95 \% \mathrm{CI}$} & \multirow[b]{2}{*}{$P$ value } & \multirow[b]{2}{*}{ OR } & \multicolumn{2}{|c|}{$95 \% \mathrm{CI}$} & \multirow[b]{2}{*}{$P$ value } \\
\hline & & Lower & Upper & & & Lower & Upper & \\
\hline Age & 0.98 & 0.92 & 1.04 & 0.45 & - & - & - & - \\
\hline Male & 0.31 & 0.08 & 1.17 & 0.08 & - & - & - & - \\
\hline Hypertension & 1.44 & 0.35 & 5.97 & 0.61 & - & - & - & - \\
\hline Diabetes mellitus & 0.53 & 0.15 & 1.93 & 0.34 & - & - & - & - \\
\hline Hyperlipidemia & 0.4 & 0.1 & 1.53 & 0.18 & - & - & - & - \\
\hline Smoking & 1.03 & 0.23 & 4.66 & 0.97 & - & - & - & - \\
\hline ESRD & 1.6 & 0.16 & 15.8 & 0.69 & - & - & - & - \\
\hline LVEDD & 1.09 & 0.99 & 1.2 & 0.08 & - & - & - & - \\
\hline LVESD & 1.12 & 0.99 & 1.27 & 0.06 & - & - & - & - \\
\hline $\operatorname{LVEF}_{\mathrm{UCG}}$ & 0.97 & 0.9 & 1.04 & 0.35 & - & - & - & - \\
\hline AV mean PG & 1.09 & 1 & 1.19 & $0.047^{*}$ & 1 & 0.9 & 1.12 & 0.97 \\
\hline TRPG & 1.02 & 0.96 & 1.09 & 0.46 & - & - & - & - \\
\hline LHRs & 1.2 & 1.05 & 1.38 & $0.008^{*}$ & 1.2 & 1.03 & 1.39 & $0.02 *$ \\
\hline LHRr & 0.99 & 0.89 & 1.1 & 0.82 & - & - & - & - \\
\hline Marked RV uptake & 1.18 & 0.94 & 1.49 & 0.99 & - & - & - & - \\
\hline EDVs & 1.07 & 1.02 & 1.12 & $0.003^{*}$ & 1.1 & 1.02 & 1.13 & $0.01^{*}$ \\
\hline ESVs & 1.07 & 1.02 & 1.12 & $0.008^{*}$ & - & - & - & - \\
\hline LVEFs & 0.98 & 0.94 & 1.02 & 0.27 & - & - & - & - \\
\hline EDVr & 1.06 & 1.01 & 1.11 & $0.02^{*}$ & - & - & - & - \\
\hline ESVr & 1.06 & 1.01 & 1.1 & $0.008^{*}$ & - & - & - & - \\
\hline LVEFr & 0.97 & 0.93 & 1.01 & 0.13 & - & - & - & - \\
\hline
\end{tabular}

Table 4. Univariate and multivariate analyses of SSS contributors in logistic regression. SSS, summed stress score; $L H R$ s or $r$, lung/heart ratio after stress or at rest; $E D V$, end-diastolic volume; $E S V$, end-systolic volume; $L V E F$, left ventricular ejection fraction. Other abbreviations as Tables $1-3$. ${ }^{*} P<0.05$.

distribution in patients with AS, which tended to be lower in some regions than in patients without significant $\mathrm{CAD}^{18,19}$.

Dipyridamole induced perfusion defects was not uncommon in our overall AS cohort, although mostly mild, and SSS was positively correlated with degree of AS. An increasing number of studies have investigated MBF and MFR obtained from dynamic imaging protocols in recent years. Rajappen et al. reported that the decrease in MFR was correlated with the severity of AS and increased hemodynamic load, but not left ventricular hypertrophy $(\mathrm{LVH})^{4}$. Furthermore, in whom post-AVR, the increase in hyperemic MBF and MFR was directly related to the increase in $\mathrm{AV}$ area ${ }^{20}$. Burwash et al. found that low-flow, low-gradient AS was characterized by higher resting $\mathrm{MBF}$ and reduced MFR, which were related to the severity of $\mathrm{AS}^{6}$. Carpeggiani et al. also found depressed MBF and MFR in severe AS patients, yet they were independent of $\mathrm{LVH}$ and $A V \mathrm{PG}^{15}$. No improvement of myocardial perfusion was noted despite the decrease in LV mass after interventions. We also noted similar phenomenon.

In the current study, we demonstrate that increased LHRs and LV volumes contributed to dipyridamole-induced perfusion abnormalities. LV size reflects the LV remodeling process. An increased lung to heart ratio (LHR) on stress MPI is a predictor of adverse cardiac events and identifies people with extensive CAD. It has been demonstrated to reflect stress-induced LV dysfunction in previous studies ${ }^{21,22}$.

LV diastolic function in patients with aortic stenosis. The peak velocities of transmitral flow at early filling (E) to A (E/A ratio) reversal was noted in majority of patients with native valves, but not significantly correlated to the presence of $\mathrm{LVH}$ or systolic dysfunction (LVEDD and $\mathrm{LVEF}_{\mathrm{UCG}}, P>0.05$ ). Diastolic dysfunction starts before systolic dysfunction in patients with aortic valve disease ${ }^{23,24}$. In our study, most patients with native valves were in the earlier stages of AS, although with preserved LVEF, diastolic dysfunction are rather common.

Difference in LVEF measurements by UCG and SPECT. Quantification of LVEF and LV volumes using gated SPECT was a reliable complementary tool ${ }^{25,26}$. Several factors may affect the accuracy, including LV size ${ }^{27-29}$, gender $^{30-32}$, perfusion defects ${ }^{33,34}$ and technological issues. ${ }^{201} \mathrm{Tl}$ is known to be a suboptimal radiopharmaceutical for gated SPECT because of low myocardial count densities and lower image resolution may create problems, especially in small hearts, in delineating the LV cavity ${ }^{35}$. Higher prevalence of small hearts (ESVs $\left.<20 \mathrm{ml}\right)$ in mild AS group.

LVEF by 2-dimensional echocardiography with modified Simpson's biplane measurement were not routinely performed. LVEF and volumetric data derived by M-mode echocardiography are less accurate because by M-mode echocardiography has limitations, including 1) the mathematic and geometric assumptions used to derive the volumes from which the ejection fraction is calculated, and 2) the lack of applicability to asynergic ventricles $^{36}$. These might be explained by LVEF differences between two methods. 


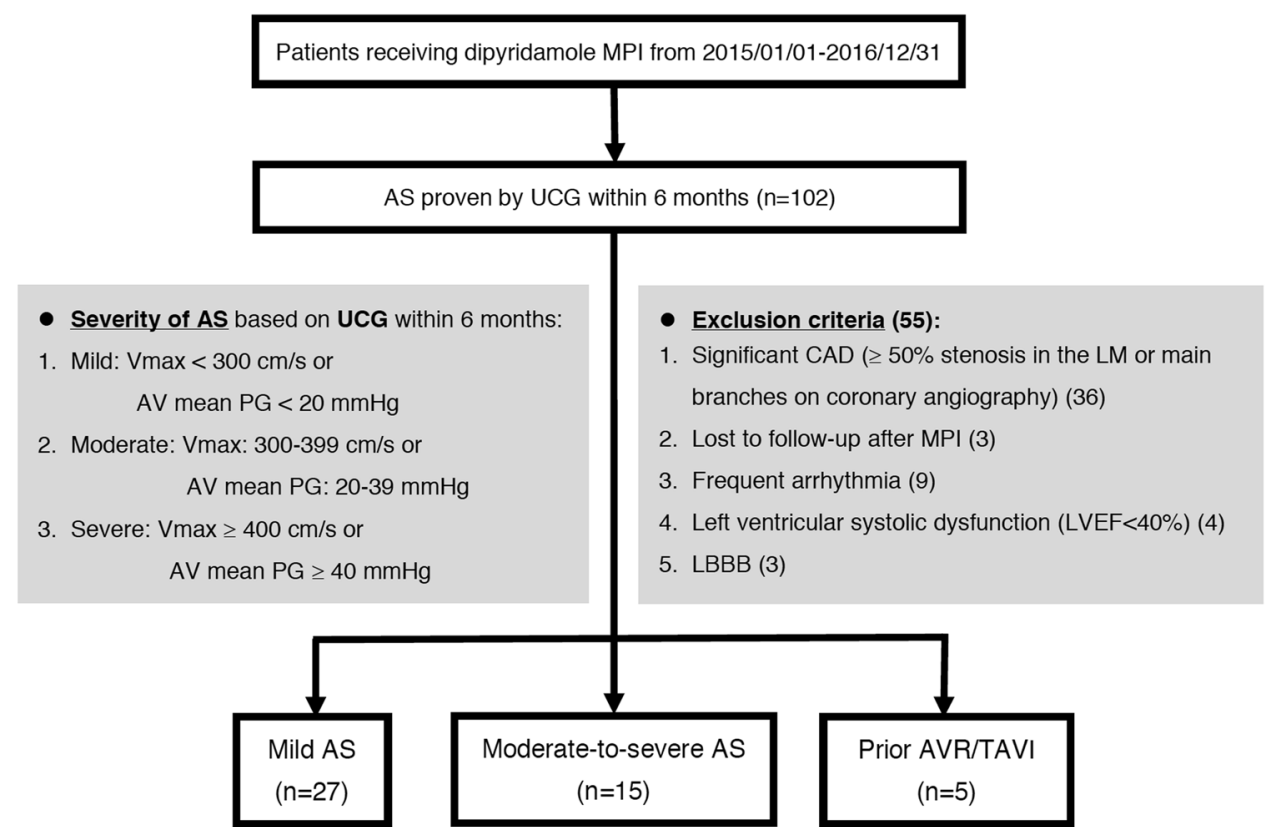

Figure 2. The inclusion algorithm of the study population. A total of 47 patients with both CZT-based MPI and Doppler echocardiography were included. MPI, myocardial perfusion imaging; UCG, echocardiography; $C A D$, coronary artery disease; $L M$, left main; $L V E F$, left ventricular ejection fraction; $L B B B$, left bundle branch block.

Indications and contraindications for MPI in Patients with aortic stenosis. Although the American College of Cardiology/American Heart Association Guidelines recommend that patients with AS having equivocal symptoms should receive modified exercise tests ${ }^{5}$, the role of vasodilator stress agents in these patients is controversial. In the current study, none of the AS patients experienced severe adverse events with unstable hemodynamics, which is similar to prior studies ${ }^{10,12-14,18,37,38}$. Scarsini et al. revealed substantial agreement between stress MPI and fractional flow reserve (FFR) and high negative predictive value (NPV) in identifying coronary lesions ${ }^{39}$. Our findings agreed that vasodilator stress can be a valuable tool to evaluate dipyridamole-induced ischemia in patients with AS and guide the treatment strategy.

Limitations. This study was a retrospective study with a relatively small number of patients conducted at a single tertiary medical center, and therefore referral bias exists. The majority of patients had mild and moderate AS. We excluded patients with known significant CAD and impaired LV systolic function, thus the severity of ischemia and dipyridamole related adverse effects could be less severe than previous reports. Due to the retrospective nature, not all patients had coronary angiography within 6 months, and LVEF by two-dimensional echocardiography with modified Simpson's biplane measurement were not routinely performed. Besides the small sample size, the interval between AV intervention and MPI was heterogeneous.

Further studies are merit to investigate the use of dipyridamole MPI in patients with severe AS, pre and post $\mathrm{AV}$ intervention, with a larger population and longer follow-up.

\section{Methods}

Study population and study design. This study was approved by the Institutional Review Board of Far Eastern Memorial Hospital (107167-E). The need for written informed consent was waived due to the retrospective nature of the study. All procedures and methods were performed in accordance with the updated guidelines and regulations. We retrospectively analyzed data from the database of a medical center in Taiwan. We reviewed all patients who underwent ECG-gated dipyridamole MPI using a cadmium-zinc-telluride camera between 2015 and 2016, and those with valvular AS diagnosed by UCG and preserved LV function within 6 months were included. The inclusion algorithm of the study population is shown in Fig. 2. Patients with known CAD (those with coronary stenosis $\geq 50 \%$ in left main or three main branches, or who received previous $\mathrm{PCI} /$ coronary artery bypass surgery (CABG) without evidence of patent stents or grafts in the last 6 months), $\mathrm{LVEF}_{\mathrm{UCG}}<40 \%$, or loss of follow-up after MPI were excluded. To reduce the interference to ECG-gated SPECT imaging analysis, those with left bundle branch block (LBBB) or frequent arrhythmia, which meant frequent atrial or ventricular premature contractions (APCs or VPCs) or atrial fibrillation (Af) were also kept out of the study. The demographic data included age, sex, cardiac risk factors (hypertension, diabetes mellitus, hyperlipidemia, and smoking), and other comorbidities (end-stage renal disease, chronic obstructive pulmonary disease or asthma, post-pacemaker implantation, and right bundle branch block). Based on the AV mean PG and AV peak velocity ( $\left.\mathrm{V}_{\max }\right)$ recorded on UCG in the last 6 months, the population was divided into three groups: (1) mild AS (AV $V_{\max }<300 \mathrm{~cm} / \mathrm{s} \mathrm{or}$ $\mathrm{AV}$ mean $\mathrm{PG}<20 \mathrm{mmHg}$ ), (2) moderate-to-severe $\mathrm{AS}\left(\mathrm{AV} \mathrm{V}_{\max } \geq 300 \mathrm{~cm} / \mathrm{s}\right.$ or $\mathrm{AV}$ mean $\mathrm{PG} \geq 20 \mathrm{mmHg}$ ), and 
(3) with prior AVR or TAVI. The clinical characteristics, safety of dipyridamole stress and MPI parameters were compared between the groups.

Resting echocardiography. Resting echocardiography was performed by experienced cardiologists. M-mode and two-dimensional Doppler imaging data were collected. LA and LV dimensions and related indexes were measured. Diastolic parameters including E and A waves, derived E/A ratio, deceleration time (DT) at early filling and tricuspid regurgitation pressure gradient (TRPG) were recorded.

Stress protocols and electrocardiogram-gated SPECT MPI. All patients were stable at the time of stress imaging, and they all received dipyridamole infusion over 4 minutes at a dose of $0.56 \mathrm{mg} / \mathrm{kg}$. A dose of $2 \mathrm{mCi}(74 \mathrm{MBq})$ thallium-201 was then injected at the 7 th minute. The injected dose was $2.5 \mathrm{mCi}(92.5 \mathrm{MBq})$ if the patient weighed more than $90 \mathrm{~kg}$, and $3.0 \mathrm{mCi}(111 \mathrm{MBq})$ if they weighed more than $100 \mathrm{~kg}$. At the 10th minute, routine 75-125 mg of aminophylline was injected intravenously for dipyridamole-induced adverse effects. Imaging began within 5 minutes after the aminophylline injection and was repeated 4 hours later. ECG, oxygen saturation and blood pressure were continuously monitored during the stress test. The development of any arrhythmia, ST segment changes, significant blood pressure (BP) changes or symptoms were recorded. ECG-gated SPECT MPI was performed in the supine position using a cadmium-zinc-telluride gamma camera (Discovery NM530c, GE Healthcare, Chicago, Illinois, USA) which was equipped with 19 pinhole collimators and 19 solid-state cadmium-zinc-telluride detectors along a 180-degree arc. Each detector was $8 \times 8 \mathrm{~cm}$ in size, and projections were obtained using a $32 \times 32$ matrix $(2.46 \times 2.46 \mathrm{~mm}$ in size $)$. The energy window was set as default for thallium-201: asymmetrically $(-14 \%$ to $+23 \%)$ at $70 \mathrm{keV}$, and symmetrically $(-9 \%$ to $+9 \%)$ at $167 \mathrm{keV}$. ECG-gating was also implemented using a built-in system ${ }^{40-42}$. Images were reconstructed with a maximum likelihood expectation maximization-based iterative algorithm (30 iterations for gated images, 70 iterations for non-gated images) using a Butterworth filter (order 15, cut-off frequency 0.28$)^{43,44}$.

Imaging analysis. SPECT quantitative perfusion and quantitative gated SPECT (QPS/QGS) software (Cedars-Sinai Medical Center, Los Angeles, CA) was used to analyze the gated images. Perfusion defects were read using a 17-segment model; segmental uptake was assessed using a 5 -point scoring system (from $0=$ normal uptake to $4=$ absent uptake). SSS, SRS and SDS were derived. In addition, LHR, LVEF, volumetric and right ventricular (RV) uptake data were also calculated.

Safety. Aminophylline injection was given in routine to resolve the side effect or to prevent late onset adverse effect during scanning. The safety of dipyridamole stress was assessed according to hemodynamic response, significant changes in ECG, stress-induced attacks of asthma or chronic obstructive pulmonary disease, and any adverse events recorded during the stress and rest tests. A significant hemodynamic response was defined as hypotension ( $\mathrm{BP}<90 \mathrm{mmHg}$ ) and a drop in systolic blood pressure $>40 \mathrm{mmHg}$ after stress. Dipyridamole-induced arrhythmia and ST-T changes such as premature contraction, atrioventricular block, ST depression and T wave inversion were recorded. Chest pain and chest tightness were classified as chest discomfort. Dizziness, head fullness, headache or heavy headiness were classified as head discomfort. Other categories of side effects included abdominal discomfort, dyspnea, body soreness and hot flushes.

Statistical analysis. Continuous variables are reported as mean \pm standard deviation and categorical data as percentages, apart from post-AVR/TAVI time which is presented as median (range). Differences in continuous variables among groups were compared using analysis of variance (ANOVA) or the Kruskal-Wallis test, based on normal or non-normal data. The chi-square test was used for categorical data. Power transformation was performed to transform non-normal variables into normal variables. To determine the contributions of SSS, SRS and SDS, linear correlation and the logistic regression analyses focusing on SSS were performed. Besides the impact of AV severity, multivariate regression analysis was carried out to adjust for other covariates, using variables with $P<0.05$ in univariate analysis. For parameters in collinearity, we chose one representative factor to undergo multivariate analysis. A $P$ value $<0.05$ was considered to be statistically significant. To assess relationships between AS severity and perfusion defects, the parameter AV mean PG was further separated by cutoff points of $20 \mathrm{mmHg}$. In addition, SSS data were also classified as being normal $(\mathrm{SSS}<4)$ and abnormal $(\mathrm{SSS} \geq 4)$, and logistic regression was used to analyze the contributors. Bland-Altman plot was further performed to compare the difference between LVEFr and $\mathrm{LVEF}_{\mathrm{UCG}}$. SPSS 22 (IBM, USA) was used for the statistical analysis.

\section{Conclusions}

Dipyridamole stress is clinically feasible with a reasonable degree of safety in patients with mild and moderate AS. Dipyridamole-induced perfusion abnormalities in patients with AS are not uncommon, but are mostly mild and in correlated to the AS severity. Valvular AS may be a potential cause of microvascular dysfunction. A normal MPI in a patient with documented AS could help clinicians to exclude the presence of obstructive CAD.

New knowledge gained. Dipyridamole stress MPI could be safe in patients with mild and moderate AS. Normal MPI results can be helpful to exclude the possibility of CAD.

\section{Data Availability}

The data are available from the corresponding author on reasonable request. 


\section{References}

1. Eveborn, G. W., Schirmer, H., Heggelund, G., Lunde, P. \& Rasmussen, K. The evolving epidemiology of valvular aortic stenosis. The Tromso study. Heart 99, 396-400 (2013).

2. Stewart, B. F. et al. Clinical factors associated with calcific aortic valve disease. Cardiovascular health study. J Am Coll Cardiol 29, 630-634 (1997)

3. Marcus, M. L., Doty, D. B., Hiratzka, L. F., Wright, C. B. \& Eastham, C. L. Decreased coronary reserve: a mechanism for angina pectoris in patients with aortic stenosis and normal coronary arteries. N Engl J Med 307, 1362-1366 (1982).

4. Rajappan, K. et al. Mechanisms of coronary microcirculatory dysfunction in patients with aortic stenosis and angiographically normal coronary arteries. Circulation 105, 470-476 (2002).

5. Otto, C. M. \& Bonow, R. O. In Braunwald's heart disease: a textbook of cardiovascular medicine (eds Douglas L. Mann et al.) 1446-1523 (Elsevier/Saunders, 2015).

6. Burwash, I. G. et al. Myocardial blood flow in patients with low-flow, low-gradient aortic stenosis: differences between true and pseudo-severe aortic stenosis. Results from the multicentre TOPAS (Truly or Pseudo-Severe Aortic Stenosis) study. Heart 94, $1627-1633$ (2008).

7. Maganti, K., Rigolin, V. H., Sarano, M. E. \& Bonow, R. O. Valvular heart disease: diagnosis and management. Mayo Clin Proc 85, 483-500 (2010).

8. Osnabrugge, R. L. et al. Aortic stenosis in the elderly: disease prevalence and number of candidates for transcatheter aortic valve replacement: a meta-analysis and modeling study. J Am Coll Cardiol 62, 1002-1012 (2013).

9. Nishimura, R. A. et al. 2017 AHA/ACC Focused update of the 2014 AHA/ACC Guideline for the management of patients with valvular heart disease: a report of the American College of Cardiology/American Heart Association Task Force on Clinical Practice Guidelines. J Am Coll Cardiol 70, 252-289 (2017).

10. Samuels, B., Kiat, H., Friedman, J. D. \& Berman, D. S. Adenosine pharmacologic stress myocardial perfusion tomographic imaging in patients with significant aortic stenosis. Diagnostic efficacy and comparison of clinical, hemodynamic and electrocardiographic variables with 100 age-matched control subjects. J Am Coll Cardiol 25, 99-106 (1995).

11. Joint Task Force on the Management of Valvular Heart Disease of the European Society of, C. et al. Guidelines on the management of valvular heart disease (version 2012). Eur Heart J 33, 2451-2496 (2012).

12. Cremer, P. C. et al. Stress positron emission tomography is safe and can guide coronary revascularization in high-risk patients being considered for transcatheter aortic valve replacement. J Nucl Cardiol 21, 1001-1010 (2014).

13. Hussain, N. et al. An assessment of the safety, hemodynamic response, and diagnostic accuracy of commonly used vasodilator stressors in patients with severe aortic stenosis. J Nucl Cardiol 24, 1200-1213 (2017).

14. Demirkol, M. O., Yaymaci, B., Debes, H., Basaran, Y. \& Turan, F. Dipyridamole myocardial perfusion tomography in patients with severe aortic stenosis. Cardiology 97, 37-42 (2002).

15. Carpeggiani, C. et al. Coronary flow reserve in severe aortic valve stenosis: a positron emission tomography study. J Cardiovasc Med (Hagerstown) 9, 893-898 (2008).

16. Pfisterer, M., Muller-Brand, J., Brundler, H. \& Cueni, T. Prevalence and significance of reversible radionuclide ischemic perfusion defects in symptomatic aortic valve disease patients with or without concomitant coronary disease. Am Heart J 103, 92-96 (1982).

17. Kupari, M. et al. Exclusion of coronary artery disease by exercise thallium-201 tomography in patients with aortic valve stenosis. Am J Cardiol 70, 635-640 (1992).

18. Rask, P. et al. Computer-assisted evaluation of dipyridamole thallium-201 SPECT in patients with aortic stenosis. J Nucl Med 35 , 983-988 (1994).

19. Francisco, D. A. et al. Tomographic thallium-201 myocardial perfusion scintigrams after maximal coronary artery vasodilation with intravenous dipyridamole. Comparison of qualitative and quantitative approaches. Circulation 66, 370-379 (1982).

20. Rajappan, K. et al. Functional changes in coronary microcirculation after valve replacement in patients with aortic stenosis. Circulation 107, 3170-3175 (2003).

21. Bingham, J. B., McKusick, K. A., Strauss, H. W., Boucher, C. A. \& Pohost, G. M. Influence of coronary artery disease on pulmonary uptake of thallium-201. Am J Cardiol 46, 821-826 (1980)

22. Homma, S., Kaul, S. \& Boucher, C. A. Correlates of lung/heart ratio of thallium-201 in coronary artery disease. J Nucl Med 28, 1531-1535 (1987).

23. Lund, O. et al. Left ventricular systolic and diastolic function in aortic stenosis. Prognostic value after valve replacement and underlying mechanisms. Eur Heart J 18, 1977-1987 (1997).

24. Elahi, M. M. et al. One problem two issues! Left ventricular systolic and diastolic dysfunction in aortic stenosis. Ann Transl Med 2, $10(2014)$

25. Harpaz, D., Asman, A., Kuperstein, R., Boaz, M. \& Chouraqui, P. Left ventricular ejection fraction assessment by Tl-201 gated SPECT: a comparison with echocardiography. Clin Cardiol 33, E56-62 (2010).

26. Coupez, E. et al. Validation of cadmium-zinc-telluride camera for measurement of left ventricular systolic performance. J Nucl Cardiol 25, 1029-1036 (2018).

27. Vallejo, E., Dione, D. P., Sinusas, A. J. \& Wackers, F. J. Assessment of left ventricular ejection fraction with quantitative gated SPECT: accuracy and correlation with first-pass radionuclide angiography. J Nucl Cardiol 7, 461-470 (2000).

28. Ford, P. V., Chatziioannou, S. N., Moore, W. H. \& Dhekne, R. D. Overestimation of the LVEF by quantitative gated SPECT in simulated left ventricles. J Nucl Med 42, 454-459 (2001).

29. Feng, B., Sitek, A. \& Gullberg, G. T. Calculation of the left ventricular ejection fraction without edge detection: application to small hearts. J Nucl Med 43, 786-794 (2002).

30. Rozanski, A. et al. Development and application of normal limits for left ventricular ejection fraction and volume measurements from 99mTc-sestamibi myocardial perfusion gates SPECT. J Nucl Med 41, 1445-1450 (2000).

31. Manrique, A., Hitzel, A., Gardin, I., Dacher, J. N. \& Vera, P. Impact of Wiener filter in determining the left ventricular volume and ejection fraction using thallium-201 gated SPECT. Nucl Med Commun 24, 907-914 (2003).

32. Wang, S. Y., Cheng, M. F., Hwang, J. J., Hung, C. S. \& Wu, Y. W. Sex-specific normal limits of left ventricular ejection fraction and volumes estimated by gated myocardial perfusion imaging in adult patients in Taiwan: a comparison between two quantitative methods. Nucl Med Commun 32, 113-120 (2011).

33. Vera, P., Koning, R., Cribier, A. \& Manrique, A. Comparison of two three-dimensional gated SPECT methods with thallium in patients with large myocardial infarction. J Nucl Cardiol 7, 312-319 (2000).

34. Vallejo, E. et al. Reproducibility and accuracy of gated SPECT for determination of left ventricular volumes and ejection fraction: experimental validation using MRI. J Nucl Med 41, 874-882; discussion 883-876 (2000).

35. Tadamura, E. et al. Assessment of regional and global left ventricular function by reinjection T1-201 and rest Tc-99m sestamibi ECG-gated SPECT: comparison with three-dimensional magnetic resonance imaging. J Am Coll Cardiol 33, 991-997 (1999).

36. ASE Workflow \& Lab Management Taskforce et al. The American Society of Echocardiography Recommendations for Cardiac Chamber Quantification in Adults: A Quick Reference Guide from The ASE Workflow and Lab Management Task Force, https:// asecho.org/wp-content/uploads/2018/08/WFTF-Chamber-Quantification-Summary-Doc-Final-July-18.pdf.

37. Patsilinakos, S. P. et al. Adenosine stress myocardial perfusion tomographic imaging in patients with significant aortic stenosis. $J$ Nucl Cardiol 11, 20-25 (2004). 
38. Parastatidis, I. \& Lerakis, S. The use of vasodilator myocardial perfusion imaging in severe aortic stenosis: Is it time for a new prospective study? J Nucl Cardiol 24, 1214-1215 (2017).

39. Scarsini, R. et al. Correlation between intracoronary physiology and myocardial perfusion imaging in patients with severe aortic stenosis. Int J Cardiol 292, 162-165 (2019).

40. Bocher, M. et al. A fast cardiac gamma camera with dynamic SPECT capabilities: design, system validation and future potential. Eur J Nucl Med Mol Imaging 37, 1887-1902 (2010).

41. Ko, C. L. et al. Data-driven respiratory motion tracking and compensation in CZT cameras: a comprehensive analysis of phantom and human images. J Nucl Cardiol 22, 308-318 (2015).

42. Ko, K. Y. et al. Clinical significance of right ventricular activity on treadmill thallium-201 myocardial single-photon emission computerized tomography using cadmium-zinc-telluride cameras. Nucl Med Commun 37, 650-657 (2016).

43. Tsai, S. Y., Wang, S. Y., Shiau, Y. C. \& Wu, Y. W. Mechanical dyssynchrony and diastolic dysfunction are common in LVH: a pilot correlation study using Doppler echocardiography and CZT gated-SPECT MPI. Scientific reports 8, 4182 (2018).

44. Lin, W. L., Wang, S. Y., Shiau, Y. C. \& Wu, Y. W. The clinical usefulness of phase analysis in detecting coronary artery disease using dipyridamole thallium-201-gated myocardial perfusion imaging with a cadmium-zinc-telluride camera. J Nucl Cardiol (2018).

\section{Acknowledgements}

We thank Ya-Huang Chen, Chia-Wen Lai, Chao-Chun Huang, Po-Wei Li for image acquisition and ECG-gated SPECT analyses. This study was partly supported by grants MOST 104-2314-B-418-008, 105-2325-B-418-001 and 107-2314-B-418 -006-MY3 from the Ministry of Science and Technology of Taiwan, and Far Eastern Memorial Hospital (FEMH 104-2314-B-418-008, 105-2628-B-418 -002-MY2 and 107-2314-B-418 -006-MY3). The funders had no role in study design, data collection and analysis, decision to publish, or preparation of the manuscript.

\section{Author Contributions}

Y.-W.W. conceived and designed the research, reviewed data, and made critical revision of the manuscript; Y.W.W. and F.-S.L. managed echocardiographic data; Y.-W.W., F.-S.L., S.-Y.W. and Y.-C.S. managed MPI data; F.S.L. collected data, performed the statistical analysis and drafted the manuscript. All authors had reviewed the manuscript.

\section{Additional Information}

Supplementary information accompanies this paper at https://doi.org/10.1038/s41598-019-48901-y.

Competing Interests: The authors declare no competing interests.

Publisher's note: Springer Nature remains neutral with regard to jurisdictional claims in published maps and institutional affiliations.

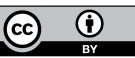

Open Access This article is licensed under a Creative Commons Attribution 4.0 International

License, which permits use, sharing, adaptation, distribution and reproduction in any medium or format, as long as you give appropriate credit to the original author(s) and the source, provide a link to the Creative Commons license, and indicate if changes were made. The images or other third party material in this article are included in the article's Creative Commons license, unless indicated otherwise in a credit line to the material. If material is not included in the article's Creative Commons license and your intended use is not permitted by statutory regulation or exceeds the permitted use, you will need to obtain permission directly from the copyright holder. To view a copy of this license, visit http://creativecommons.org/licenses/by/4.0/.

(C) The Author(s) 2019 